\title{
Gene silencing in HIV-1 latency by polycomb repressive group
}

Hyeon Guk Kim ${ }^{1 \dagger}$, Kyung-Chang Kim ${ }^{1,4 \dagger}$, Tae-Young Roh',3, Jihwan Park², Kyung-Min Jung ${ }^{1}$, Joo-Shil Lee ${ }^{1}$, Sang-Yun Choi ${ }^{4}$, Sung Soon Kim ${ }^{1}$ and Byeong-Sun Choi ${ }^{{ }^{*}}$

\begin{abstract}
Background: The persistence of latently Human immunodeficiency virus-1 (HIV-1) infected cellular reservoirs in resting $\mathrm{CD}^{+} \mathrm{T}$ cells is a major obstacle to HIV-1 eradication. The detailed mechanism of HIV-1 latency remains unclear. We investigated histones and their post-translational modification associated with HIV-1 latency in novel HIV-1 latently infected cell lines established previously, NCHA cells.
\end{abstract}

Methods: To examine histones and their modification linked with HIV-1 latency, the expression profiles for core histone proteins and histone deacetylases (HDACs) in NCHA cells were characterized by RT-PCR, ELISA, and western blot. The levels of histone acetylation and methylation at histone H3 Lys ${ }^{9}$ (H3K9) and Lys ${ }^{27}$ (H3K27) in HIV-1 latently infected cells were analyzed by western blot and chromatin immunoprecipitation-sequencing (ChIP-seq).

Results: The expression levels for four core histone proteins (H2A, H2B, H3 and H4) and HDACs (HDAC1-8) in NCHA cells were not significantly different from those in their parental cells. Histone H3K9 and H3K27 acetylations in NCHA cells showed no difference in parental and NCHA cells, whereas the levels of di- and tri-methylation were increased in NCHA cells. The expression of EED which is a component of polycomb repressive complex 2 (PRC2), and BMI1 and RING2 which are constituents of PRC1, were upregulated in NCHA cells. In addition, more ubiquitylation at histone H2A was detected in NCHA cells.

Conclusions: Our results suggest that tri-methylation of histone $\mathrm{H} 3 \mathrm{~K} 27$ and $\mathrm{H} 2 \mathrm{~A}$ ubiquitylation via polycomb group protein may play a crucial role in epigenetic silencing accounting for HIV-1 latency in NCHA cells.

\section{Background}

HIV-1 can evade the immune responses of host cells and establish latent infection among HIV-infected patients, which leads to AIDS despite treatment referred to a highly active antiretroviral therapy (HAART). Latently infected memory $\mathrm{T}$ cells, which are generally established within days of the initial infection, are very rare ( 1 million) in a patient and have a long half-life of over 44 months on average. The complete elimination of HIV reservoirs seems to take over 60 years under the HAART regimen [1].

In some HIV-1 latency studies, phosphorylation of $\mathrm{NF}-\kappa \mathrm{B}$ p65 activates the long terminal repeat (LTR) of HIV-1 provirus in latent cells directly, which in turn

\footnotetext{
* Correspondence: byeongsun@korea.kr

† Contributed equally

'Division of AIDS, Center for Immunology and Pathology, Korea National Institute of Health, Chung-buk, Republic of Korea

Full list of author information is available at the end of the article
}

drives HIV-1 transcription. Phosphorylation of p65 at $\operatorname{ser}^{276}$ enhances the recruitment of coactivator p300/ HAT, leading to increased transcriptional activation in $\mathrm{NF}-\kappa \mathrm{B}$ dependent genes by the acetylation of histones $[2,3]$. NF- $\kappa \mathrm{B}$ p50/HDAC complexes which constitutively bind to the HIV-1 LTR and maintain HIV latency can be depleted from the latent HIV promoter upon TNF- $\alpha$ induction [4]. Even if some researchers have reported that HDACs play a critical role in HIV-1 latency, molecular mechanisms involved in HIV-1 latency should be further explored for complete eradication of HIV.

The eukaryotic genome is organized into the highly complex nucleoprotein structure of chromatin. Epigenetic studies show that this chromatin structure can be modified by DNA methylation, covalent histone modifications, and nucleosome remodeling. In particular, histone proteins consisting of the nucleosome core are subject to modifications such as methylation, acetylation, ubiquitylation, sumoylation, and phosphorylation
C Biomed Central 
on specific residues [5]. Posttranslational modifications of core histones change their interactions with DNA and thus involve in diverse biological processes such as DNA repair, chromosome condensation, and gene regulation. Specifically, histone $\mathrm{H} 3 \mathrm{Lys}^{4}$ tri-methylation (H3K4me3) is mostly enriched at active gene promoters, whereas histone $\mathrm{H} 3 \mathrm{~K} 9$ and $\mathrm{H} 3 \mathrm{~K} 27 \mathrm{di}$-/tri-methylation (H3K9me2/me3 and H3K27me2/me3) are highly enriched at inactive loci in mammalian cells [6].

Recent cancer studies show that broad alteration of gene activation or silencing by epigenetic alterations can lead to cancer development and carcinogenesis [7]. Elevated expression levels of some histone methyltransferase such as EZH2 and G9a are associated with breast and liver cancers $[8,9]$. It has been suggested that HIV-1 latency is strongly associated with chromatin silencing and that novel drug development can be based on the chromatin modification like acetylation/ deacetylation and methylation as new targets for HIV1 therapy $[1,10,11]$. Recently, it was reported that G9a, one of histone methyltransferase, and $\mathrm{p}$-TEFb contribute to the maintenance and establishment of HIV-1 latency [12,13]. In our previous study, HIV-1 latently infected cells also showed distinctly different patterns in histone H3K9 and H3K27 modification from those in their HIV-uninfected parental cells (unpublished data). Based on these findings, we tried to figure out the detailed mechanisms of HIV-1 silencing in the cellular reservoirs for curing HIV-1 infection from AIDS patients in the future.

\section{Materials and methods Cell lines}

Reference cell lines, A3.01 cells and ACH2 cells, were obtained from the National Institutes of Health AIDS Research and Reference Reagent Program. Latently infected A3.01-derived cell lines, NCHA1 and NCHA2, were established from our laboratory [14]. Cells were cultured in RPMI 1640 culture medium supplemented with $10 \%$ fetal bovine serum (FBS), $5 \%$ penicillin/streptomycin, and $2 \mathrm{mM}$ glutamine at $37^{\circ} \mathrm{C}$ in humidified $5 \%$ $\mathrm{CO} 2$ incubator.

\section{RNA extraction and RT-PCR}

TRIZol reagent (Invitrogen, USA) was used for isolation of RNA according to the manufacturer's protocol. Extracted RNA was stored at $-20^{\circ} \mathrm{C}$ prior to use for RTPCR. Total RNA (2ug) collected from each cell line was reverse transcribed to cDNA with Superscript II Reverse Transcriptase (Invitrogen) and an oligo(dT) primer.

\section{Preparation of nuclear extracts}

Nuclear extracts were prepared with Nuclear Extraction Kit (Panomics, USA) and protein concentration of these nuclear extracts was measured with Protein DC assay Kit (Bio-Rad, USA) according to the manufacturer's protocol. Nuclear extracts were applied to ELISA assay immediately and the rest were stored at $-80^{\circ} \mathrm{C}$ prior to use.

\section{ELISA assay for histone acetylation}

Acetylation levels of four core histones were measured with Pathscan Acetyl Histone H2A, H2B, H3 and H4 Sandwich ELISA Kit (Cell Signaling, USA) according to the manufacturer's instruction.

\section{Western blot analysis}

To identify HDAC proteins, total cellular protein extracts were prepared in ice-cold RIPA buffer $(50 \mathrm{mM}$ Tris pH 7.5, 0.5\% deoxycholate, 0.5\% NP-40, 0.5\% SDS, and $100 \mathrm{mM} \mathrm{NaCl}$ ) supplemented with fresh Complete $^{\mathrm{TM}}$ protease inhibitor cocktail (Roche, Swiss). Protein extracts were separated by SDS-PAGE, transferred to an Immobilon ${ }^{\mathrm{TM}}-\mathrm{P}$ membrane (Millipore, USA), and probed with specific antibodies $(\mathrm{H} 2 \mathrm{~A} \sim \mathrm{H} 4, \mathrm{HDACs}$ and EED, Abcam, USA; ubiquitylated H2A, Millipore, USA). GAPDH (\#2118, cell signaling, USA) and Lamin B (sc20682, Santa Cruz, USA) were used as protein loading control. After incubation with the HRP-conjugated secondary antibody, proteins were visualized using West Pico chemiluminescence substrate (Pierce, USA) according to the manufacture's protocol.

\section{Immunoprecipitation}

Immunoprecipitation was performed using IP Kit (Active motif, USA) with mouse anti-BMI1 (ab14389, Abcam, USA). The interaction of RING2 with BMI1 was examined with western blot using rabbit antiRING2 (ab28629, Abcam, USA).

\section{Chromatin immunoprecipitation (ChIP)}

Chromatin from uninfected and latently infected CD4+ $\mathrm{T}$ cells was digested with micrococcal nuclease into nucleosome-size unit. ChIP was performed using antibodies to histone H3K4me3 (ab8580, Abcam, USA), H3K9me3 (ab8898, Abcam, USA), H3K27me3 (07-449, Millipore, USA), and H3K9ac (ab4441, Abcam, USA). Following treatment of proteinase $\mathrm{K}$, the DNA fragments were purified by phenol/chloroform extraction and ethanol precipitation.

\section{Genomic DNA library construction for ChIP-Seq and data analysis}

The DNA sequencing library preparation and sequencing on the Genome Analyzer II were performed according to the manufacturer's instruction (Illumina, USA). Briefly, the ChIPed DNA was polished by blunting and ' $\mathrm{A}$ '-base addition followed by adapter ligation. 
After sequencing, the GA pipeline 1.4 software provided by Illumina was used for image analysis, base calling, and sequence alignment. The uniquely aligned sequence tags to the human genome (hg18/NCBI build 36) were used in further analysis. The sequence tags were counted in promoters (transcription start site $\pm 1 \mathrm{~kb}$ ), genebodies (from transcription start site $+1 \mathrm{~kb}$ to transcription end site), and intergenic regions. To analyze the enrichment patterns of histone modifications on HIV-1 provirus, we aligned the sequencing tags to the HIV-1 genome and counted tags in a non-0verlapping 200bp window.

\section{Results}

Histone and HDAC levels in NCHA cells were not significantly different

The expression and acetylation levels of four core histones (H2A, H2B, H3 and H4) in NCHA cells did not exhibit significant differences as shown in Figrue 1A and $1 \mathrm{~B}$, respectively. The mRNA levels for HDACs in Class I (HDAC1, 2, 3, and 8) were measured by RTPCR analysis shown in Figure 1C. Both Class I and Class II HDACs (HDAC4, 6, and 7; data not shown) did not show any significant difference in parental and latently HIV-1 infected cells. The protein levels of HDAC1 - 3 in ACH2 and NCHA cells were relatively similar to those observed in their parent cells (Figure 1D; data not shown for HDAC4, 6, 7 and 8).

Histone methylations were highly enriched in NCHA cells As shown in Figure 2A, the levels of di- and trimethylation of histone H3K9 and H3K27 were dramatically elevated in NCHA cells except $\mathrm{ACH} 2$ cells. To determine whether the elevation of $\mathrm{H} 3 \mathrm{~K} 9 \mathrm{me} 3$ and $\mathrm{H} 3 \mathrm{~K} 27 \mathrm{me} 3$ levels were biased in specific genomic regions, the genome-wide distribution of modifications were examined
(A)

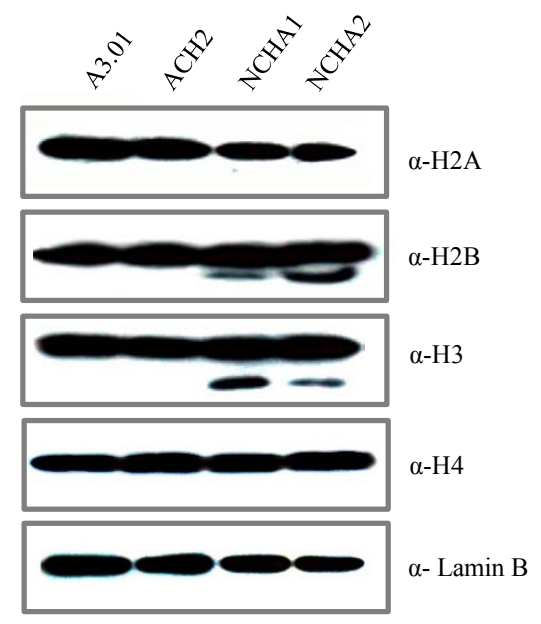

(C)

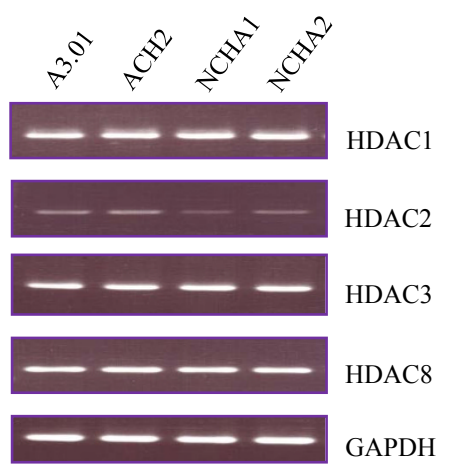

(B)

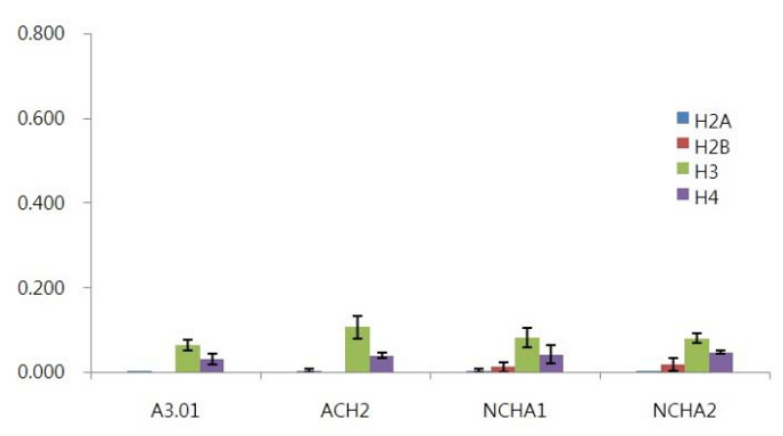

(D)

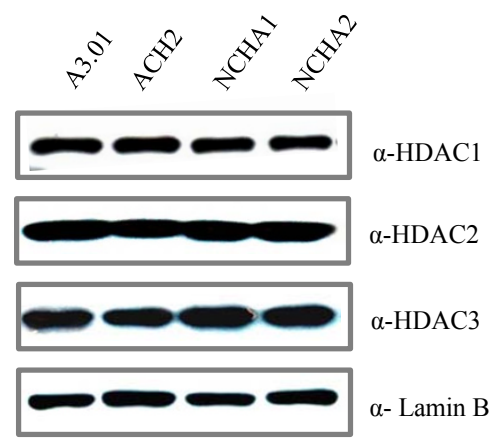

Figure 1 Histone and HDAC profiles in HIV-1 latently infected A3.01derived cells. A) Expression levels of four core histone proteins were investigated by western blot. Thirty ug of nuclear extract were loaded and immunoblotted using antibodies specific to $\mathrm{H} 2 \mathrm{~A}, \mathrm{H} 2 \mathrm{~B}, \mathrm{H} 3$ and $\mathrm{H} 4$. Anti-laminB was used as a loading control. B) The acetylation levels of four core histone proteins were quantified using the H2A-, H2B-, H3- and H4 -PathScan acetylated histone sandwich ELISA kit. Error bar represent the S.D. from the mean. C) mRNA levels of HDACs in each cell line were measured with reverse transcriptase PCR (RT-PCR). GAPDH was used as a control. D) Protein levels of HDAC1, HDAC2 and HDAC3 were investigated by western blot using 30 ug of nuclear extract. Anti-laminB was used as a loading control. 


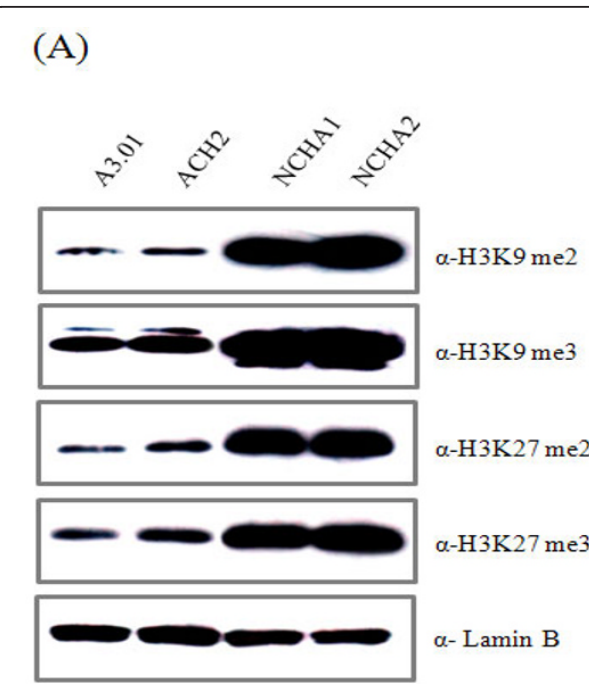

(C)

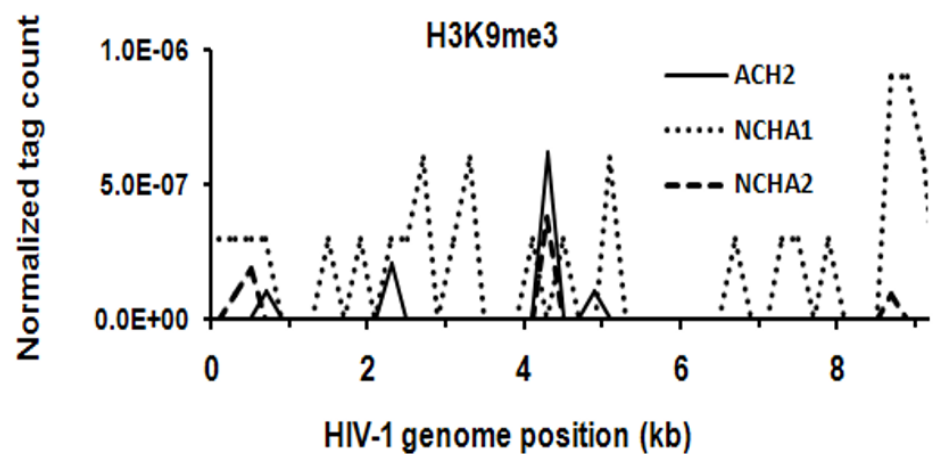

Figure 2 Gene silencing by polycomb group-proteins in NCHA cells for HIV-1 latency. A) Methylation levels of histone H3 on the specific lysine residues were measured by western blot. In each lane, $30 \mathrm{ug}$ of nuclear extract were used and the antibodies were indicated on the right. Anti-laminB was used as a loading control. B) Global distributions of histone modifications were examined by ChIP-Seq. Promoters were the regions of $1 \mathrm{~kb}$ upstream and downstream of the transcription start site, and gene body was defined as the length from $1 \mathrm{~kb}$ downstream of the transcription start site to transcription end site and the remaining regions were intergenic regions. C) The H3K9me3 profile was shown on HIV-1 provirus genome. The $\mathrm{X}$ axis represents the HIV-1 genomic position and the $\mathrm{Y}$ axis indicates the normalized tag count which is calculated by total tag numbers detected in a $1 \mathrm{~kb}$ window divided by total sequenced tag number.

using all RefSeq genes (Figure 2B). H3K4me3 and $\mathrm{H} 3 \mathrm{~K} 9 \mathrm{ac}$ were highly enriched in promoter regions, whereas $\mathrm{H} 3 \mathrm{~K} 9 \mathrm{me} 3$ and $\mathrm{H} 3 \mathrm{~K} 27 \mathrm{me} 3$ were distributed over the gene bodies and intergenic regions. However, the overall population was not significantly changed in $\mathrm{ACH} 2$ and NCHA cells compared with those of the A3.01 cells. The histone modification patterns of the HIV-1 proviral genomes showed that $\mathrm{H} 3 \mathrm{~K} 9 \mathrm{me} 3$ was enriched in latently infected cell lines (ACH2, NCHA1, and NCHA2) shown in Figure $2 \mathrm{C}$ but H3K27me3 was not (data not shown).

\section{Polycomb group might induce HIV-1 gene silencing}

To understand HIV-1 latency related with gene silencing by polycomb group protein complex, we examined the
(B)

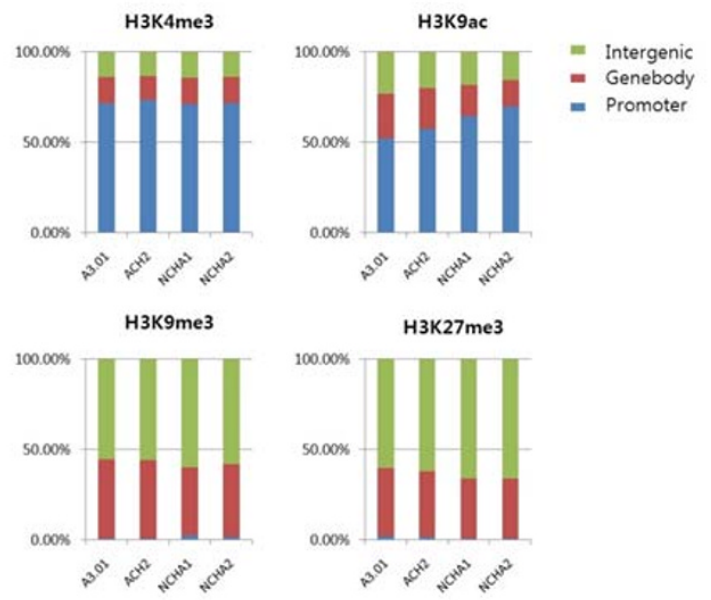

expression levels of polycomb group proteins in NCHA cells. Firstly, the expression level of EED, which is part of PRC2 that recognizes histone H3K27 and/or H3K9 residues for histone methylation, was investigated by western blot using an antibody specific to EED. As shown in Figure 3A, the expression of EED was upregulated in NCHA cells. Secondly, the expression levels of BMI1 and RING2, which are components of PRC1 that recognizes and binds to $\mathrm{PRC} 2$, were also increased in the nuclear fraction of NCHA cells compared with their parent cells and the interaction between these two proteins was confirmed by coimmunoprecipitation (Figure 3B). Finally, ubiquitylation levels of NCHA cells on histone $\mathrm{H} 2 \mathrm{~A}$ were also enriched compared with the parent cells (Figure $3 \mathrm{C}$ ). These results suggest that PRC- 


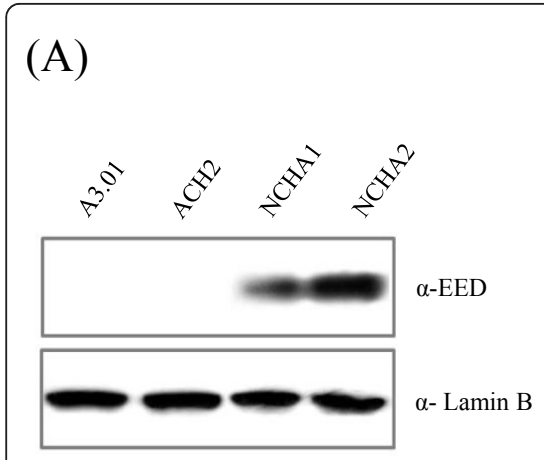

(B)

(C)
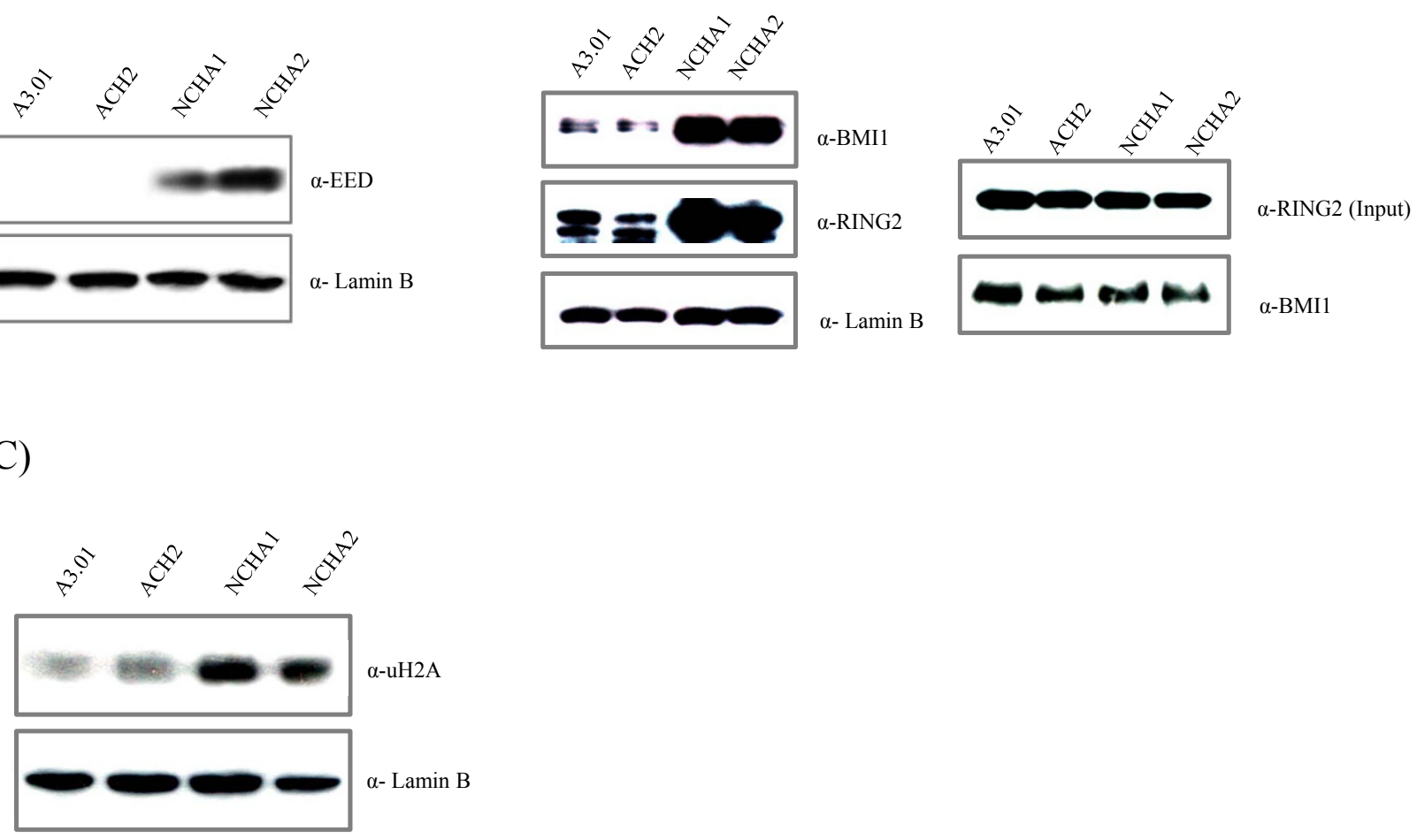

Figure 3 Induction of HIV-1 gene silencing by polycomb group proteins. A) Expression levels of EED, one of PRC2 components, were measured by western blot. Thirty ug of nuclear extract were also used. The antibodies were indicated on the right. B) The expression levels of polycomb group proteins, BMI1 and RING2, were examined by western blot. The right panel showed coimmunoprecipitation experiment, immunoprecipitated with RING2 antibody and blotted with BMI1 antibody. C) Ubiquitylation levels of all cell lines were investigated by western blot. Using $30 \mathrm{ug}$ of nuclear extract and antibody against ubiqutylated histone H2A. Anti-laminB was used as a loading control.

mediated repressive $\mathrm{H} 3 \mathrm{~K} 27$ methylation and $\mathrm{H} 2 \mathrm{~A}$ ubiquitylation may contribute to HIV-1 gene silencing in NCHA cells.

\section{Discussion}

Current antiretroviral therapies, including HAART, do not completely eradicate latent reservoirs of HIV-1 from patients, even though they suppress new HIV-1 replication effectively. The best way to eliminate this reservoir completely is to reactivate HIV-1 latently infected cells by inducing the expression of HIV-1 provirus. Many studies have reported potential antireservoir therapies to reactivate HIV-1 latently infected cells using HDAC inhibitors [15-17], interleukin-7 (IL-7) [18,19], hexamethyl-bisacetamide (HMBA) [20], and prostratin [21]. Eukaryotic genomes are organized into the chromatin structure with repeated nucleosomes, which consist of $\sim 146$ base pairs of DNA wrapped around an octamer of core histones (H3, H4, H2A, and H2B) [22]. Chromatin structure can be varied by DNA methylation and posttranslational histone modifications. These modifications are important for the regulation of cellular transcription, DNA replication, and repair [5,6]. Although some reports suggest that the chromatin structure at the HIV1 integration site and LTR region plays a major role in HIV-1 postintegration latency [23,24], the molecular linkage between HIV-1 latency and epigenetic control, especially histone modifications, is not fully understood. In this study, to identify the epigenetic relevance to HIV-1 latency, we investigated core histones and histone modification factors such as HDACs, which were reported as critical factors in the maintenance of HIV-1 latency. As shown in Figure 1, the expression levels of four core histones and HDACs did not exhibit significantly differences in $\mathrm{ACH} 2$ and $\mathrm{NCHA}$ cells comparing to those in their parent cells. These results suggest that the protein amount of histones and HDACs in NCHA cells may not be associated with HIV-1 latency even though several studies have suggested HDACs-related HIV-1 latency models [3,4].

Interestingly, $\mathrm{H} 3 \mathrm{~K} 9 \mathrm{me} 2 / \mathrm{me} 3$ and $\mathrm{H} 3 \mathrm{~K} 27 \mathrm{me} 2 / \mathrm{me} 3$ were highly enriched in HIV-latent cells. To determine whether the enrichment of H3K9me3 and H3K27me3 in NCHA cells was specific to certain genomic regions, the distribution of histone methylations was examined in a genome-wide level. H3K4me3 and H3K9ac showed high 
enrichment in promoter regions, whereas $\mathrm{H} 3 \mathrm{~K} 9 \mathrm{me} 3$ and H3K27me3 were spread out over gene bodies and intergenic regions. However, these patterns were not significantly changed in $\mathrm{ACH} 2$ and NCHA cells compared with those of A3.01 cells. To identify the chromatin states of HIV-1 proviral genome, we analyzed the histone methylation patterns at $\mathrm{H} 3 \mathrm{~K} 9$ and $\mathrm{H} 3 \mathrm{~K} 27$. High enrichment of H3K9me3 was observed in HIV-1 infected latent cells, whereas there was no enrichment H3K27me3. Our results show the possibility that the HIV-1 genome silencing may be mainly caused by H3K9me3-mediated process and the host cell genomes, especially in NCHA cells, can be regulated by both H3K9me3 and H3K27me3. These gene repression through histone methylations were consistent with the previous report showing that histone H3K27 trimethylation correlated with gene silencing in human T cells [25].

Polycomb group (PcG)-proteins mediated gene silencing is mainly established by histone H3K27 methylation. PcG proteins, which were first identified in Drosophila melanogaster, are required for the maintenance of HOX gene cluster repression during development. They induce transcriptional gene silencing in higher eukaryote and act as a global chromatin regulator [26-28]. PcG proteins consist of two different complexes, which are termed polycomb repressive complex 1 (PRC1) and 2 (PRC2) [27,28]. PRC1 is formed by over 10 different proteins including BMI1 and RING1A/B and ubiquitylates histone $\mathrm{H} 2 \mathrm{~A}$ by the E3 ubiquitin ligase activity of RING1A/B for silencing. PRC2 is a smaller complex that comprises three main proteins (EZH2, EED and SUZ12) and catalyzes histone H3K27me3 [29,30]. Recently, it was also reported that carboxy terminal domain of EED plays important role in binding to tri-methyl lysine residue of histone tails and is indispensable for the binding of PRC2 complex to repressive marks [31]. According to the known PcG-mediated silencing mechanism, PRC2 recruits PRC1 to target genes via the binding of PRC1 to histone H3K27me3. Subsequently, PRC1 catalyzes the ubiquitylation of $\mathrm{H} 2 \mathrm{~A}$ and may lead to specific gene silencing. Recently, it was reported that BMI1 play an important role in the maintenance of HSV-1 latency [32]. To elucidate the HIV-1 latency related to H3K27me3 in more detail, we examined the expression levels of EED, BMI1 and RING2 all of which were enriched in NCHA cells and the interaction of BMI1 and RING2 was identified. Also, the ubiquitylation levels of histone $\mathrm{H} 2 \mathrm{~A}$ in NCHA cells were increased compared with the parent cells. These results suggest that PRC-mediated repressive H3K27 methylation, $\mathrm{H} 3 \mathrm{~K} 27 \mathrm{me}$, and H2A ubiquitylation may contribute to HIV-1 gene silencing in NCHA cells.

\section{Conclusion}

Newly established NCHA cells harboring latent HIV-1 showed the enrichment of histone H3K27 methylation, histone H2A ubiquitylation, and PcG proteins expression. Therefore, our result demonstrates that tri-methylation of H3K27 and $\mathrm{H} 2 \mathrm{~A}$ ubiquitylation via polycomb repressive complexes should be involved in HIV-1 latency and contribute to epigenetic gene silencing.

\section{Acknowledgements}

This work was supported by an intramural grant from the Korea National Institute of Health (Grant Nos. 2007-N51001-00 and 2010-N51001-00) and in part by the World Class University program via the National Research Foundation of Korea, funded by the Ministry of Education, Science and Technology (Grant No. R31-2008-000-10105-0, T-Y. Roh).

\section{Author details}

'Division of AIDS, Center for Immunology and Pathology, Korea National Institute of Health, Chung-buk, Republic of Korea. ${ }^{2}$ Division of Molecular and Life Sciences. ${ }^{3}$ Division of Integrative Biosciences and Biotechnology, Pohang University of Science and Technology (POSTECH), Gyeongbuk, Republic of Korea. ${ }^{4}$ School of Life Science and Biotechnology, Korea University, Seoul, Republic of Korea.

\section{Authors' contributions}

BSC and HGK conceived the project and designed experiments. HGK and KCK carried out research, wrote the manuscript and prepared the figures. KMJ, TYR and JP carried out CHIP and CHIP-seq. JSL, SYC and SSK helped to draft the manuscript. All authors approved the final manuscript.

\section{Competing interests}

The authors declare that they have no competing interests.

Received: 28 December 2010 Accepted: 18 April 2011 Published: 18 April 2011

\section{References}

1. Williams SA, Greene WC: Host factors regulating post-integration latency of HIV. Trends Microbiol 2005, 13:137-139.

2. Vermeulen L, De Wilde G, Van Damme P, Vanden Berghe W, Haegeman G: Transcriptional activation of the NF-kappaB p65 subunit by mitogenand stress-activated protein kinase-1 (MSK1). EMBO J 2003, 22:1313-1324.

3. Zhong H, May MJ, Jimi E, Ghosh S: The phosphorylation status of nuclear NF-KB determines its association with CBP/p300 or HDAC-1. Mol Cell 2002, 9:625-636.

4. Williams SA, Chen LF, Kwon H, Ruiz-Jarabo CM, Verdin E, Greene WC: NF-KB p50 promotes HIV latency through HDAC recruitment and repression of transcriptional initiation. EMBO J 2006, 25:139-149.

5. Sharma S, Kelly TK, Jones PA: Epigenetics in cancer. Carcinogenesis 2010, 31:27-36.

6. Kouzarides T: Chromatin modifications and their function. Cell 2007, 128:693-705

7. Chi P, Allis AD, Wang GG: Covalent histone modifications - miswritten, misinterpreted and mis-erased in human cancers. Nature reviews cancer 2010, 10:457-469.

8. Kondo Y, Shen L, Ahmed S, Boumber Y, Sekido Y, Haddad BR, Issa JP: Downregulation of histone $\mathrm{H} 3$ lysine 9 methyltransferase G9a induces centrome disruption and chromosome instability in cancer cells. PLoS One 2008, 3:e2037.

9. Yonemitsu Y, Imazeki F, Chiba T, Fukai K, Nagai Y, Miyagi S, Arai M, Aoki R, Miyazaki M, Nakatani Y, Iwama A, Yokosuka O: Distinct expression of polycomb group proteins EZH2 and BMI1 in hepatocellular carcinoma. Hum Pathol 2009, 40:1304-1311.

10. Varier RA, Kundu TK: Chromatin modifications (acetylation/deacetylation/ methylation) as new targets for HIV therapy. Curr Pharm Des 2006, 12:1975-1993. 
11. Colin L, Van Lint C: Molecular control of HIV-1 postintegration latency: implications for the development of new therapeutic strategies. Retriviro 2009, 6:111-129.

12. Imai K, Togami H, Okamoto T: Involvement of histone H3 lysine 9 (H3K9) methyltransferase G9a in the maintenance of HIV-1 latency and its reactivation by BIX01294. J Biol Chem 2010, 285:16538-16545.

13. Tyagi M, Pearson RJ, Karn J: Establishment of HIV latency in primary CD4+ cells is due to epigenetic transcriptional silencing and P-TEFb restriction. J Viro 2010, 84:6425-6437.

14. Kim KC, Kim HG, Jung KM, Roh TY, Park J, Lee JS, Choi SY, Kim SS, Choi BS: The Effect of CD4 Receptor Downregulation and its Downstream Signaling Molecules on HIV-1 Latency. Biochem Biophysic Researc Communi 2011, 404:645-651.

15. Matalon S, Palmer BE, Nold MF, Furlan A, Kassu A, Fossati G, Mascagni P, Dinarello CA: The histone deacetylase inhibitor ITF2357 decreases surface CXCR4 and CCR5 expression on CD4(+) T-cells and monocytes and is superior to valproic acid for latent HIV-1 expression in vitro. J AIDS 2010, 54:1-9.

16. Edelstein LC, Micheva-Viteva S, Phelan BD, Dougherty JP: Short communication: activation of latent HIV type 1 gene expression by suberoylanilide hydroxamic acid (SAHA), an HDAC inhibitor approved for use to treat cutaneous T cell lymphoma. AIDS Res Hum Retrovir 2009, 25:883-887.

17. Archin NM, Keedy KS, Espeseth A, Dang H, Hazuda DJ, Margolis DM: Expression of latent human immunodeficiency type 1 is induced by novel and selective histone deacetylase inhibitors. AIDS 2009, 23:1709-1806.

18. Scripture-Adams DD, Brooks DG, Korin YD, Zack JA: Interleukin-7 induces expression of latent human immunodeficiency virus type 1 with minimal effects on T-cell phenotype. J Virol 2002, 76:13077-13082.

19. Wang FX, Xu Y, Sullivan J, Souder E, Argyris EG, Acheampong EA, Fisher J, Sierra M, Thomson MM, Najera R, Frank I, Kulkosky J, Pomerantz RJ, Nunnari G: IL-7 is a potent and proviral strain-specific inducer of latent HIV-1 cellular reservoirs of infected individuals on virally suppressive HAART. J Clin Invest 2005, 115:128-137.

20. Choudhary SK, Archin NM, Margolis DM: Hexamethylbisacetamide and disruption of human immunodeficiency virus type 1 latency in CD4 (+) T cells. J Infect Dis 2008, 197:1162-1170.

21. Rullas J, Bermejo M, García-Pérez J, Beltán M, González N, Hezareh M, Brown SJ, Alcamí J: Prostratin induces HIV activation and downregulates HIV receptors in peripheral blood lymphocytes. Antivir Ther 2004, 9:545-554

22. Luger K, Richmond TJ: DNA binding within the nucleosome core. Curr Opin Struct Biol 1998, 8:33-40.

23. Jordan A, Bisgrove D, Verdin E: HIV reproducibly establishes a latent infection after acute infection of T cells in vitro. EMBO J 2003, 22:1868-1877.

24. Lewinski MK, Yamashita M, Emerman M, Ciuffi A, Marshall H, Crawford G, Collins F, Shinn P, Leipzig J, Hannenhalli S, Berry CC, Ecker JR, Bushman FD: Retroviral DNA integration: viral and cellular determinants of target-site selection. PLOS Pathog 2006, 2:e60.

25. Roh TY, Cuddaph S, Cui K, Zhao K: The genomic landscape of histone modifications in human T cells. Proc Natl Acad Sci USA 2006, 103:15782-15787.

26. Lewis EB: A gene complex controlling segmentation in Drosophila. Nature 1978, 276:565-570

27. Boyer LA, Plath K, Zeitlinger J, Brambrink T, Medeiros LA, Lee TI, Levine SS, Wernig M, Tajonar A, Ray MK, Bell GW, Otte AP, Vidal M, Gifford DK, Young RA, Jaenisch R: Polycomb complexes repress developmental regulators in murine embryonic stem cells. Nature 2006, 441:349-353.

28. Simon JA, Kingston RE: Mechanisms of Polycomb gene silencing: knowns and unknowns. Nat rev mol cell boil 2009, 10:697-708.

29. Cao R, Tsukada $Y$, Zhang $Y$ : Role of Bmi-1 and Ring1 A in $\mathrm{H} 2 \mathrm{~A}$ ubiquitylation and Hox gene silencing. Mol Cell 2005, 20:845-854.

30. Wang $H$, Wang L, Erdjument-Bromage $H$, Vidal $M$, Tempst $P$, Jones RS, Zhang Y: Role of histone H2A ubiquitination in Polycomb silencing. Nature 2004, 431:873-878.

31. Margueron R, Justin N, Ohno K, Sharpe ML, Son J, Drury WJ, Voigt $P$ Martin SR, Taylor WR, De Marco V, Pirrotta V, Reinberg D, Gamblin SJ: Role of the polycomb protein EED in the propagation of repressive histone marks. Nature 2009, 461:762-767.
32. Kwiatkowski DL, Thompson HW, Bloom DC: The polycomb group protein Bmi1 binds to the herpes simplex virus 1 latent genome and maintains repressive histone marks during latency. J Virol 2009, 83:8173-8181.

doi:10.1186/1743-422X-8-179

Cite this article as: Kim et al.: Gene silencing in HIV-1 latency by polycomb repressive group. Virology Journal 2011 8:179.

\section{Submit your next manuscript to BioMed Central and take full advantage of:}

- Convenient online submission

- Thorough peer review

- No space constraints or color figure charges

- Immediate publication on acceptance

- Inclusion in PubMed, CAS, Scopus and Google Scholar

- Research which is freely available for redistribution

Submit your manuscript at www.biomedcentral.com/submit
C Biomed Central 